\title{
Can Digital Technologies Create a Stronger Model for Democratic Participation? The Case of CrowdLaw
}

\author{
Helene Langlamet \\ Annenberg School for Communication \\ University of Pennsylvania \\ helene.langlamet@asc.upenn.edu
}

\begin{abstract}
This study attempts to critically assess the democratizing potential of "CrowdLaw," a form of online participation that its practitioners describe as crowdsourced policy-making. To do so, the study analyzes both the statements of Crowdlaw practitioners gathered at the third "online global conference on \#CrowdLaw" and the design and performance of the CrowdLaw platforms for which the author could find a sufficiently complete online presence. Findings about the democratizing potential of CrowdLaw are mixed: on the one hand, the analysis of practitioners' statements reveals an intention to create broad participation, and discussion forums that encourage deliberation. On the other, a look at the platforms' design and performance reveals an uneven and incomplete implementation of these intentions.
\end{abstract}

\section{Introduction}

The democratizing promise of the Internet has been a familiar trope since the beginning of the Internet. Scholars have both hoped and doubted that it could act as an extension of the public sphere [1-4]. With digital technology becoming increasingly ubiquitous, initiatives to democratize participation have sprouted up everywhere in workplace or in government settings [5]. Some have made the case that the Internet will make government more democratic by making citizen engagement more feasible [6-8]. Others have been more cautious, arguing that widespread enthusiasm about the Internet as a magic tool to increase participation has yet to be followed up by any true changes in the participatory structure of government [5]. A large literature has emerged pointing out that the Internet has not only a decentralizing logic, but also a centralizing logic through its data collection and processing capabilities $[9,10]$.

Given these debates, surprisingly little has been written about the bulk of these "democratizing" innovations that have attempted to alter existing decision-making structures. The writing that has attempted to survey some of these new approaches to participation usually starts from the assumption that Web 2.0 tools are democratizing $[6,11]$. Some critical work on online participation systems does exist in academia, but it is usually on systems developed by the researchers themselves [12, 13]. Very little critical work on approaches developed outside of the academic setting exists yet.

This study is an attempt to fill this gap, by examining a selection of projects featured in the third "online global conference on CrowdLaw," a conference organized by the Governance Lab (or GovLab for short), a research lab based at NYU's Tandon School of Engineering. The projects all share in common the same feature, which their proponents claim to be a democratizing innovation: a "CrowdLaw platform," an online space created in order to crowdsource policy ideas from lay citizens. CrowdLaw, according to the GovLab's website, is "open, collaborative crowdsourced lawmaking," a "tech-enabled approach for drafting legislation or constitutions" that provides a channel for regular citizens to contribute to policymaking [14].

Using all the evidence that could be collected on the CrowdLaw projects (including CrowdLaw practitioners' statements that the author could find during and outside of the conference, and available data about some of the platforms' design and performance that could be found online), the author scrutinizes both the theoretical assumptions underpinning CrowdLaw practitioners' intervention, and the functioning of their platforms, in order to attempt to answer the question of whether "CrowdLaw platforms" are capable of living up to their alleged democratizing potential.

\subsection{The CrowdLaw model}

The CrowdLaw projects are noteworthy because of the very particular position that they occupy in the 
network of Web 2.0 participation innovators: To begin with, the conference brought together projects from eight different countries and four different continents, and featured government actors, entrepreneurs, party representatives, think tanks, a representative from the U.N., and private citizens. The GovLab, the research lab that featured them, is a pretty important actor in the open governance movement that gained some steam under the Obama administration: Most notably, its founder, Beth Noveck, was appointed the first United States Deputy Chief Technology Officer under President Obama in 2008, and the director of the White House Open Government Initiative (2009-2011) [6]. The open governance model of partipation, as Noveck and the GovLab see it, consists of leveraging the untapped expertise of citizens in order to increase the efficacy and legitimacy of institutions [6, 15]. The vision of participation that Noveck lays out in her book Smart Citizens, Smarter State (2015), consists largely of the crowdsourcing of "citizen" skills.

However, CrowdLaw, which the Governance Lab defines as "open, collaborative crowdsourced lawmaking" [14], goes by definition beyond Noveck's model of crowdsourced participation: it is hard to imagine providing input into a legislative process that wouldn't be at least partly normative. In addition, the practitioners featured at the conference presented a model of participation that was sometimes more akin to deliberation than to conventional crowdsourcing. Deliberation is discussion with the goal of reaching a solution to a problem without an objective solution, such as a normative problem. Ideally it involves all the people who are governed by the decision and helps to find a solution that is closer to the common good [16]. Many theorists put strict restrictions on the nature of the discussion that can qualify as deliberation, but at the very least, it should involve the give and take of arguments, and the ability of participants to revise their opinions in light of evidence [17].

From the outset we can note that there is at least a potential tension between the GovLab's and Noveck's notion of participation, and the model of participation that CrowdLaw practitioners seem to ascribe to. This study finds that CrowdLaw participants' model of participation does indeed come closer to deliberation than to crowdsourcing, though in terms of their understanding of their participants and of digital technology as a tool to harness online participation, the difference from Noveck is less clear. A look at the platform interfaces works to additionally blur this distinction, and also punctures the idea that online platforms can be effective tools to harness participation in and of themselves. More importantly, the study finds no convincing evidence that the projects alter the balance of power in favor of the participants. Based on this, the study argues for an updated model of participation and for more transparency surrounding efforts from power holders to "democratize" participation.

In the next section the study attempts to situate CrowdLaw within a larger movement of e-participation initiatives that claim to be changing existing decisionmaking structures, and give a detailed description of the CrowdLaw platforms featured at the conference. Section 3 presents an analysis of CrowdLaw practitioners' statements and of the CrowdLaw platform interfaces. Section 4 will give an overview and a discussion of the findings, before ending with conclusions and recommendations.

\section{Background}

\subsection{CrowdLaw in context}

The Governance Lab defines CrowdLaw as "open, collaborative crowdsourced lawmaking" [14]. Crowdsourcing is "an open call for anyone to participate in an online task" [18]. Noveck, in her book, gives a whole series of examples of what this crowdsourcing can look like, from "citizen scientists" helping to classify images from the Hubble Space Telescope, through enlisting the help of volunteers to build crisis maps from social media reports in an environmental disaster, to building software applications that keep databases of volunteers who can perform CPR, and can alert them in case of an emergency (2015) [6]. Most of her examples have in common that they either rely on people's localized knowledge, expertise, volunteer labor, or a combination of the three. Crowdsourcing the way Noveck describes it can include examples of peer production, like Wikipedia. It also includes crowdfunding efforts like Kickstarter or Indiegogo.

CrowdLaw distinguishes itself from most of these interventions in two ways: first, it seeks to crowdsource input from participants on their policy preferences, and not just their skills, knowledge, or time. And secondly, it departs from the unidirectional mode of input in traditional crowdsourcing by attempting to encourage dialogue on its platforms. Aitamurto and Landemore (2016) do perhaps the best job at characterizing the type of participation that CrowdLaw practitioners are trying to generate on their platforms: they call it crowdsourced deliberation, and describe it as "an open, asynchronous, depersonalized, and distributed kind of online deliberation occurring among self-selected participants in the context of an attempt by government or another organization to open up the policymaking or lawmaking process" (p.174) [19]. Perhaps surprisingly, the most prevalent kind of intervention that could qualify as 
crowdsourced deliberation is crowdsourced or participatory constitution making. Crowdsourced constitution making efforts attempt to involve the public in the drafting or revision of their constitution, sometimes in more participatory ways by allowing them input into the process (how binding it is is another matter), and sometimes in ways that seem primarily designed to generate buy-in in the population. Judging from the literature, these participatory constitution making processes seem to be concentrated in Arab and Scandinavian countries [20-22]

\subsection{Description of the CrowdLaw platforms}

The third "online global conference on CrowdLaw" took place on September $24^{\text {th }}, 2015$, and brought together nine different speakers from eight different countries and four different continents [23] (see Table 1).

\begin{tabular}{|c|c|c|c|}
\hline $\begin{array}{l}\text { Project } \\
\text { name }\end{array}$ & Presenter & $\begin{array}{l}\text { Country of } \\
\text { application }\end{array}$ & $\begin{array}{l}\text { Included } \\
\text { in the } \\
\text { analysis? }\end{array}$ \\
\hline $\begin{array}{l}\text { Legislation } \\
\text { Lab }\end{array}$ & $\begin{array}{l}\text { Tarik Nesh Nash, } \\
\text { platform developer }\end{array}$ & $\begin{array}{l}\text { Morocco, } \\
\text { Kurdistan, } \\
\text { Somalia, }\end{array}$ & yes \\
\hline $\begin{array}{l}\text { Constitucion } \\
\text { de Todos }\end{array}$ & Daniela Hirsch & Chile & yes \\
\hline $\begin{array}{l}\text { Platform } \\
\text { Libya }\end{array}$ & Sean Deely, UN & Libya & yes \\
\hline Neos Lab & $\begin{array}{l}\text { Joseph Lentsch, } \\
\text { member of Neos party } \\
\text { academy }\end{array}$ & Austria & yes \\
\hline Podemos & $\begin{array}{l}\text { Victoria Alsina, visiting } \\
\text { scholar at Harvard }\end{array}$ & Spain & yes \\
\hline / & $\begin{array}{l}\text { Ben Kallos (NYC } \\
\text { councilmember) }\end{array}$ & $\begin{array}{l}\text { United } \\
\text { States }\end{array}$ & no \\
\hline Hacker Lab & $\begin{array}{l}\text { Cristiano Ferri, } \\
\text { Brazilian house of } \\
\text { representatives }\end{array}$ & Brazil & no \\
\hline $\begin{array}{l}\text { Open } \\
\text { Ministry }\end{array}$ & $\begin{array}{l}\text { Joonas Pekkanen, } \\
\text { platform developer }\end{array}$ & Finland & yes \\
\hline $\begin{array}{l}\text { Marco Civil, } \\
\text { Plataforma } \\
\text { Brasil, } \\
\text { Mudamos }\end{array}$ & $\begin{array}{l}\text { Ronaldo Lemos, from the } \\
\text { think tank Instituto de } \\
\text { Tecnologia \& Sociedade } \\
\text { do Rio }\end{array}$ & Brazil & yes \\
\hline
\end{tabular}

\section{Table 1. Crowdlaw Projects}

It featured a broad variety of different projects: three involving constitution review platforms deployed in Chile, Kurdistan, and Libya, two spearheaded by new political parties in Spain and Austria to give their supporters an online platform for policy debate, and four projects spearheaded by two independent think tanks in Brazil and Finland intended to crowdsource citizen suggestions on specific policy issues in order to inform the legislative process of their respective countries. Two additional projects involved politicians in New York City and Brazil, and were more geared toward providing tools to politicians to reach out to the population than to extending citizens' opportunities for political participation, and so will not be considered in detail here.

Three speakers presented projects applying two different online constitution review platforms, Legislation Lab and Icon Libya. Legislation Lab is a generic online platform intended to allow participants to review and debate over the text of a constitution (or other legislation) that was deployed in different places, including Chile and Kurdistan. Icon Libya is a more complex platform that was deployed in Libya in 2011, shortly after the fall of Gaddafi, as part of a UN effort to involve the Libyan population in the post-conflict transition. The platform allows for tiered participation, allowing all platform users to seek information and express their opinion about the constitution-drafting effort, and a small minority of participants to actually help draft the constitution, or at the very least a "civil society constitution."

The projects spearheaded by the European parties, Podemos in Spain and Neos in Austria, were intended to encourage broader citizen participation in policy development. Podemos and Neos are two opposition parties that sprung up in the wake of 2011 wave of protests in Europe. Both ran on a platform of extending and strengthening democratic participation [24, 25]. Podemos' project was supported by two platforms, Plaza Podemos and Appgree, one of which was meant to provide a space for Podemos followers to deliberate, and the other one was designed to crowdsource policy proposals, and allow the public to rank them through up votes or down votes. The Neos party had the Neos Lab platform, which supports online discussion groups on different policy issues, and allows them to develop white papers on these issues.

Finally, the projects developed by independent think tanks were designed to close the gap between citizens and government in the policy-making process, by crowdsourcing policy suggestions from the population and feeding them into the legislative process. The Finnish project, Open Ministry, was launched as a response to a constitutional amendment in 2012 that guaranteed crowdsourced policy proposals with 50,000 votes or more a hearing in parliament [26]. Open Ministry was created to provide assistance to citizens and civil society organizations that needed help generating enough support for their proposals and ensuring a fair hearing for them in parliament. The Brazilian think thank Institute for Technology and Society Rio developed three platforms, Marco Civil, Plataforma Brasil, and Mudamos, to crowdsource popular input on specific policy issues. The Marco Civil platform was meant to elicit popular feedback on Internet policy, and was deployed as part of the process that resulted in the passage of the "Marco Civil da Internet" legislation in 
2014 [27], and the Plataforma Brasil and Mudamos platforms were meant to elicit feedback on issues of political reform and public security.

\section{Analysis}

This section will go over the available evidence to tell whether CrowdLaw lives up to its democratizing potential. Section 3.1 will go over practitioners' discourse about CrowdLaw, and section 3.2 will review existing CrowdLaw platform interfaces.

\subsection{What practitioners tell us about CrowdLaw}

3.1.1. Method of discourse analysis. To gain a more critical understanding of the CrowdLaw model of online participation, and of its potential to democratize the process of legislation drafting, the study starts by examining the conference participants' discourse on CrowdLaw, in order, on the one hand, to tease out practitioners' understandings of what CrowdLaw is and is meant to achieve, and on the other, to relate these understandings to academic models of online participation, and broader scholarly theory on democracy and the Internet.

The author started by partially transcribing the statements of the seven participants whom she judged to be presenting on online participation platforms, focusing on statements about who the platform was meant to reach, and what kind of participation they wanted the platform to support, as well as how digital technology was believed to contribute to any of these things. The author then iteratively went through the transcribed statements and tried to identify the core arguments made by the participants. Once a core argument was identified, the author went through all the transcribed statements again and tried to pick out all the statements making that argument, as well as all the statements making a contradictory argument.

The findings were supplemented with two different types of supporting evidence: two pieces of outside writing by conference participants on the topic of CrowdLaw (one by Lemos et al. (2014) [28] about the Marco Civil platform, and another by Deely and Nesh Nash (2014) [29], the speakers for Icon Libya and Legislation Lab, on my.con, another constitution drafting platform), and the mission statements on the Marco Civil and Neos Lab websites.

\subsubsection{CrowdLaw participants according to practitioners. The statements of CrowdLaw} practitioners reveal that they think of the question "who do we want to include in our platforms?" ways that are broadly consistent with Noveck's model of crowdsourced online participation: in terms of the types of people that they want to involve in their online participation platforms, who they are generally stays undefined, or they are simply called "citizens" (Nesh Nash, Alsina, Pekkanen). Among the speakers, there is also an understanding that they want to extend participation to citizens who weren't previously involved in the policy-making process: Lentsch, from the Neos Lab, speaks of a "mission to find a different approach to politics, to make it more open - as an open laboratory for new politics" (29:20). Other speakers don't make their goal of extending citizen participation through technology explicit, but it is apparent, for example, in Alsina's and Pekkanen's citing of their usage statistics: Alsina claims that 15,000 people regularly use Plaza Podemos, while Pekkanen mentions that Open Ministry was involved in six out of the thirteen initiatives that reached the 50,000 vote threshold.

The speakers also share Noveck's and her research lab's assumption that digital technology is the tool of choice to harness this kind of participation. Lemos, for example, thinks of technology as a tool to promote civic participation. Nesh Nash echoes some of Noveck's bolder claims about the disruptive potential of digital technology to change our mode of governance:

We believe that Legislation Lab could be a powerful tool for participatory democracy (...) We feel we are on the verge of this disruptive change, that's had the role of closing this important gap between the governments and the public, to strengthen the culture of the rule of law (7:20 of the Crowdlaw conference).

But at another moment, Nesh Nash acknowledges the limitations of his online platform for generating participation, speaking of the need to supplement it with a mobile presence, for example. Deely speaks of the necessity to supplement the online platform with a multi-media campaign and in-person consultations and negotiations . Lemos et al. (2014), in their description of the Marco Civil process, make the same argument [28]. So while the practitioners express the same optimism about the potential of digital technology to extend political participation as Noveck does, some of them also acknowledge some limitations that the online format can have.

It is also interesting to note that when practitioners do define who the "citizens" are to whom they want to extend participation, some important differences emerge: For Hirsch, from La Constitucion de Todos, involving more people in the policy making process means not having the process confined to experts:

What I'd like to see is it becomes a little bit more common sense that anyone can participate in the 
lawmaking process and legislation process, that it's not just for specialists or just for legislators $(2: 00: 30)$.

Deely, on the other hand, puts a similar emphasis as Noveck on expertise, describing Icon Libya as a tiered participation system, where everyone can go to inform themselves and testify on their own experience, but only a few technical experts and advocates can contribute to the drafting of the constitution, or the civil society version of the constitution. And both Deely, speaking about Icon Libya, and Lemos et al. (2014), writing about Marco Civil, describe a multi-stakeholder policymaking process, where only one of the stakeholders is civil society, and other stakeholders include NGOs and universities for Icon Libya, and corporate and government actors in the case of Marco Civil [28].

One other notion of who are the intended participants surfaces in Nesh Nash's and Deely's remarks: Nesh Nash mentions an application of Legislation Lab in Kurdistan, where the platform is meant to help " a minority rights group (...) deal with the tyranny of the majority" (8:10). And Deely makes the argument that the online format allows minority groups and women to participate in the constitutionmaking process in a way that they couldn't if they had to go to a public event. Both seem to gesture at a pluralist model of participation that emphasizes equal access to political power for different groups in society $[16,30]$. Deely and Nesh Nash adopt the pluralist model more clearly in the article they co-authored about my.con in 2014:

Self-selecting representatives of civil society organizations representing minorities, people with disabilities or other traditionally marginalized groups or communities, and people with specific expertise can be invited to contribute to the drafting of particular provisions or articles or to provide feedback on drafts prepared by the responsible thematic committee or subcommittee (p.11) [29]

In summary, while most of the time practitioners remain vague about who they mean by "CrowdLaw participants," when they do specify it more clearly, it becomes apparent that their understanding of it is not straightforward, and that they may not be in agreement about what that understanding is: Some of the time, when speakers specify in more detail who their participants are, their views align with those of Noveck's, as when they see their platform's role as tapping into society's latent expertise. Sometimes, their understanding of their participants is arguably more democratic than Noveck's, as when they draw on egalitarian or pluralist notions of participation. But at other times, their description of their own platforms reveals a tiered participation system that is undemocratic.

3.1.3. The CrowdLaw model of participation according to practitioners. So far, we've seen that practitioners' notions about who their intended participants are, and how technology contributes to reaching them, largely overlap with Noveck's, with a few exceptions. In terms of the model of participation that CrowdLaw practitioners are trying to achieve, we've already seen that it deviates from Noveck's in two important way: First, because by definition it crowdsources normative input from participants. Second, because while the platforms incorporated some traditional crowdsourcing elements, with the exception of Open Ministry, all but one of the projects considered in this paper included a platform intended to facilitate discussion.

The CrowdLaw practitioners' statements mirror this departure from Noveck's model: Some of the speakers do refer to approaches that resemble traditional crowdsourcing: Deely, for example, speaks of a feature on the Icon Libya platform that would allow participants to upload 30-second videos of themselves, the best of which could be stitched together to present to drafters at the end of the constitution process. Alsina describes Appgree, one of the platforms used by Podemos, as designed to crowdsource proposals and rank them through up or down votes.

But both speakers also describe online discussion forums as part of their projects, and most of the practitioners' statements about the nature of the participation on their platforms are more consistent with political deliberation: for example, Alsina describes Plaza Podemos as "a place of contact and debate for all followers of Podemos in order to share their thoughts and ideas" (37:15). And Nesh Nash describes Reforme.ma, the precursor to Legislation Lab, as "a platform that allowed citizens to analyze and discuss the text of the constitution" (6:00). Lemos et al. (2014) even referred to the type of participation they were trying to achieve on Marco Civil as "deliberation" (p.4).

The nature of the debate, discussion or deliberation that practitioners were trying to generate on their platforms is not theorized during the conference, but a look at Deely and Nesh Nash's (2014) writing outside of the conference betrays an influence of deliberative theory that is unmistakable. For instance, they write:

[Public debate] contributes to reconciling different points of view (...) Through informed discussion and debate citizens test and challenge the opinions and arguments of others, and may be compelled to accept a particular conclusion (p.8) [26]. 
The properties they attribute to public debate bear some resemblance to the properties attributed by Chambers to deliberation:

Deliberation is debate and discussion aimed at producing reasonable, well-informed opinions in which participants are willing to revise preferences in light of discussion, new information, and claims made by fellow participants (p.309) [31].

In addition, Deely and Nesh Nash (2014) write:

Debated in public, the worth of different options can be seen by the strength of the arguments supporting them rather than which proposals are supported by the most powerful representative or the largest number of people (p.8) [29].

This argument strongly resembles Habermas' notion of the "forceless force of the better argument," which is the only form of influence accepted in his ideal speech situation (p.108) [32].

In summary, while practitioners' notion of who their platforms are meant to reach aligns with Noveck's overall, the model of participation they are trying to achieve is different from hers: while many of the CrowdLaw platforms integrate some elements that are consistent with Noveck's crowdsourcing model, a core design feature of most of the platforms is a discussion forum. Additionally, many of the practitioners see the forum's core function as facilitating deliberation, or at least a kind of discussion that resembles deliberation.

This section has looked at practitioners' intentions regarding how inclusive their platforms are supposed to be, and the type of participation they are supposed to generate. The following section will consider the available evidence to see how well their platforms actually deliver on these intentions.

\subsection{What platform design and performance tell us about CrowdLaw}

3.2.1. Method of platform analysis. As evidence of the platforms' performance, the author relied on two platforms, Legislation Lab [33] and Mudamos [34] that actually tracked their user statistics on their platforms. This was supplemented with more basic information that the Neos Lab [35] provided about the number of participants in each of its forums.

To paint a picture of the platforms' design, the author relied on the CrowdLaw platforms described by the practitioners that had a discoverable online presence, and were in a language that the author could understand, or translate. Three platforms fit this description: Legislation Lab, Neos Lab and Mudamos. The study also made some inferences about two other platform that had only a partial presence (Marco Civil [36]) or no discoverable presence online (Icon Libya), based on statements the author could find on the platform's design. In the case of Marco Civil, these inferences were drawn both from Lemos' description of the platform at the conference, and from additional descriptions of the platform that the author found on Marco Civil's home page, while in the case of Icon Libya, the author relied exclusively on Deely's descriptions at the conference, which were quite detailed.

3.2.2. What platform performance tells us about how inclusive CrowdLaw is. Going off of the available evidence, the track record for inclusivity is pretty dismal. Even by Noveck's standard of generating high participation, Crowdlaw platforms fail spectacularly: While according to Tarik Nesh Nash, 200,000 people visited his website Reforme.ma in Morocco (the prototype for Legislation Lab) within two months of the launch of the platform, according to the Legislation Lab's user statistics, the participation numbers are much humbler. The policy text on the platform that attracted the most user participation (the Chilean constitution) drew only fifty-five participants, and 243 comments for 129 articles. Mudamos and the Neos Lab fare only slightly better. Ronaldo Lemos, when describing Plataforma Brasil, the precursor to Mudamos, reported at the conference that the platform received approximately 35,000 votes. But the user statistics for Mudamos only show a participation rate of 250 people. The Neos Lab's website does not display comprehensive user statistics, but a look at their website's list of roughly one hundred theme groups reveals that about one third of them have only one participant, while only about one fifth of them have more than ten participants (with the largest rate of participation for any one group being forty-five people). These numbers seem roughly consistent with the platform's spokesperson's self-report of a few hundred participants.

Judging by the available demographic data that Legislation Lab and Mudamos provided, the platforms fail even more starkly at achieving a few of the practitioners' aspiration of creating representative participation and expanding participation to excluded groups: of the participants contributing feedback to the Chilean constitution on Legislation Lab, only 17\% of the participants were female, and on Mudamos, that proportion was $14 \%$. In addition, over fifty percent of contributors to Mudamos' discussion about public security came from the public security sector. The discussion on La Constitucion de Todos also likely attracted many participants that were not concerned in first line by the question of Chilean constitutional reform, because close to a quarter of contributors were from outside Chile. 
3.2.3. What platform design tells us about the CrowdLaw model of participation. The available data on platform use and participant demographics reveal that the CrowdLaw platforms do not seem to be the intrinsic tools to generate online participation that CrowdLaw practitioners often expect them to be. How well then do they succeed in really creating the model of participation that they describe in their statements?

The author finds from analyzing the available evidence on the five platforms mentioned in section 3.2.1. that the platforms seem to fall broadly into two types in terms of the model of participation that they encourage: The first type, comprised of Legislation Lab, Marco Civil, and Mudamos, is made up of simple platforms constructed around the single function of soliciting popular input on a single legal text. According to Lemos, and Lemos et al. (2014), the Marco Civil and Mudamos platforms are slightly more complex, in that they elicit input from participants in several phases, first on a white paper, then on the text of legislation, and that the type of input elicited is different at different phases [28]. But all three platforms have in common that at any given phase the type of participation facilitated is singletiered: in other words, all participants accessing the platform are given the same opportunities to participate.

On the other hand, the design of the platforms of the second type (Neos Lab and Icon Libya) is much more complex, incorporating multiple functions, and their participation model is two-tiered: the majority of participants are only able to submit input in a way that is discrete and unidirectional, similarly to traditional crowdsourcing. Only a minority of participants has access to more complex tasks like deliberating or contributing to the drafting of legal documents.

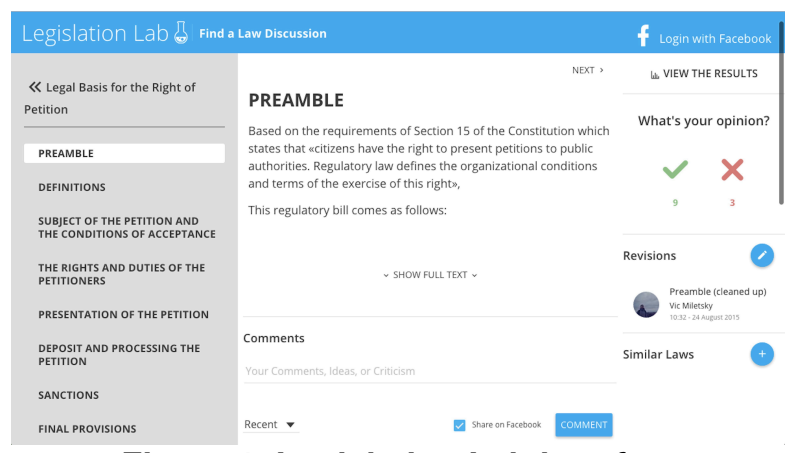

Figure 1. Legislation Lab interface

Legislation Lab (fig. 1) is the simplest of all three platforms: it has a very simple design, which allows users to leave comments, vote, or edit small sections of a law or petition, and to navigate between those sections using a menu. The voting feature is consistent with traditional crowdsourcing, but in theory, the platform also allows for deliberation, because of the comment and editing features. However, the way the platform is designed also fragments discussion by structuring the comments around small sections of a legislative text, instead of through an open forum or around broader topics. In addition, the potential for communication is limited in the revision feature, because, while it does allow for comments to be made under an edited piece of text, it requires participants to click on the profile picture of an editor in order to see the edited version of the text. This limits the extent to which the editing of the law or petition can become a communicative or collaborative process.

The basic input structure of the Marco Civil and Mudamos is the same as that of the Legislation Lab comments that can be appended to each paragraph of a legal text - thus, with the possibility for communication, but not deliberation-friendly in design. However, in contrast to Legislation Lab, both Marco Civil and Mudamos incorporate opportunities for communication between participants into their design, albeit peripherally, by redirecting longer comments or comment strings to independent discussion forums. That said, as with Legislation Lab, the platforms only allow participants to provide feedback on the law, and not to shape the text of the law directly.

In summary, what can be said about all three platforms is that they allow for fairly equal participation, but limit participants' freedom to choose the terms of their involvement, and their opportunity to participate in online discussions. While the Marco Civil and Mudamos platforms do incorporate some discussion forums into their platform, these forums are only a peripheral part of their design.

In contrast, the platforms in the second group, Neos $L a b$ and Icon Libya, allow participants to contribute directly to the drafting of legislation: For example, the Neos Lab allows some participants to join theme groups where they can participate in discussions and collectively draft white papers that are then posted on the website, under the rubric "Aktuelle Begutachtung" (Under current review). And the platform of Icon Libya has a section called "Write the constitution," where participants can either edit the text of the actual constitution or contribute to the drafting of an informal "civil constitution."

However, this function is only available to a minority of users: In the case of Neos Lab (fig. 2), participants can only join the theme group discussions by contacting the group moderators and getting vetted by them. In the case of Icon Libya, this type of participation is for the most part only open to experts, according to Deely. For the majority of users on both platforms, the opportunities provided by the design to submit input are decidedly more aggregative: In the case of the Neos Lab, the platform allows three main avenues 
for general input: submitting a suggestion form, submitting an inquiry form, and commenting on white papers put out by the discussion groups. Even then, an examination of the comments reveals that most are from participants in the theme groups, or people affiliated with the party. In the case of Icon Libya, general feedback comes mostly in the form of short videos uploaded by users to the platform, which according to Deely will then be used to create a video to present to the constitution drafters.

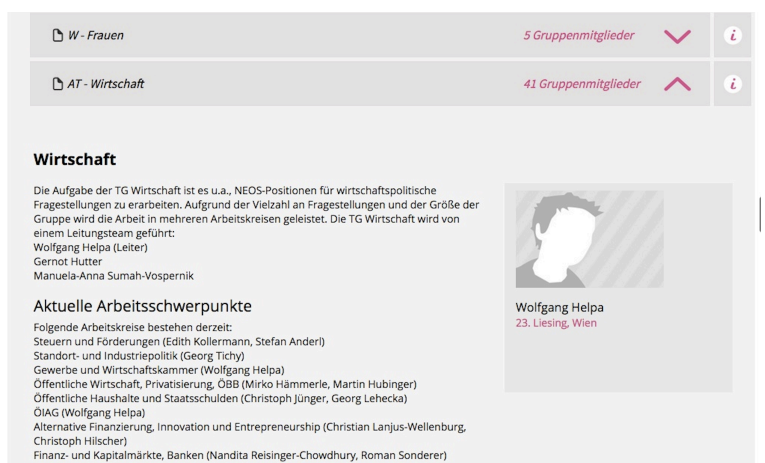

Figure 2. Neos Lab interface: Economy theme group

In summary, while the Neos Lab and Icon Libya do a better job than their counterparts at fostering an open discussion between some of their participants, these participants only constitute a minority of the users of the platform, making these features on the platforms look less like a democratic innovation and more like a privilege.

In sum, if we compare the five platforms' performance with CrowdLaw practitioners' stated goals for their platforms' performance, we find that none of them quite succeed in conforming to practitioners' stated intention: While many practitioners see their platforms as a space to facilitate deliberation, or at least a kind of discussion resembling deliberation, their platforms for the most part only facilitate discussion in a superficial way, and for the most part do not incorporate any design features intended to facilitate a deeper and more rule-based discussion - and when they do provide opportunities for more deliberative discussion, this type of participation is limited to a minority of vetted participants, who tend to be insiders already.

\section{Discussion \& Conclusion}

Proponents of CrowdLaw have made the case that it constitutes a democratizing innovation. This study asks whether CrowdLaw platforms actually live up to their democratizing potential. To answer this question, this study considers both the breadth and scope of participation that CrowdLaw practitioners want to generate and how they are actualized on the platforms.

The analysis found discrepancies between practitioners' statements and the actual functioning and interface of the platforms both in breadth and scope. In terms of breadth, practitioners made the assumption that CrowdLaw platforms would naturally attract high participation, and claimed participation numbers as high as 15,000 on their platforms, but available data on platform usage shows participation rates that never exceeded 250 people. In terms of scope of participation, for the most part practitioners agreed that they wanted to encourage discussion between participants on their platforms. Some even thought of the discussion they wanted to create in ways that were consistent with deliberation. A look at the actual platforms showed that most of them did indeed have features that allowed participants to have online conversations. But the analysis did not reveal any features that would move superficial online conversations to more deliberative ones; while some CrowdLaw practitioners did formulate some requirements on the type of conversation they wanted to encourage, these did not seem to translate into their design.

In addition to the discrepancies between practitioners' statements and platforms' performance, the analysis uncovered the following thing: participants' notion of who the participants were that they were trying to reach seemed undertheorized, and when practitioners did define who they were, it became clear that they were not of one mind: some wanted to make participation more representative or more egalitarian, explicitly stating the intention to extend participation to "non-experts", while others specifically targeted experts. Some even described a tiered model of participation, where experts and other types of insiders could have access to more expansive forms of participation, while the rest of participants only had access to a narrower, usually one-directional form of participation, more in line with conventional crowdsourcing.

\subsection{Who participates on CrowdLaw platforms?}

Judging from the available data, CrowdLaw platforms do nothing in and of themselves to generate democratic participation, much less representative democratic participation. The failure of the CrowdLaw platforms in this study to generate anything resembling robust participation stands as a stark reminder of a ubiquitous reality that is often overshadowed by our everyday experience of Internet virality: while in theory the Internet connects everyone who has an Internet connection, in most cases having an online presence 
expands one's reach only insignificantly without recourse to other (and in many cases much more timetested) means of generating participation. This phenomenon has been amply demonstrated by quantitative researchers: for example, Goel, Watts and colleagues find that less than $3 \%$ of individual communications on the Internet spread to more than four people, and mass media is still overwhelmingly responsible for the diffusion of what we think of as "viral" content on the Internet $[37,38]$.

CrowdLaw practitioners, when they obscure the low participation levels on their platforms, and to a lesser extent the GovLab and Noveck, when they treat the Internet as a kind of silver bullet for harnessing popular participation, misrepresent the contribution CrowdLaw platforms are capable of making to democracy. That said, the idea that CrowdLaw platforms could be a "democratic innovation" need not be discarded altogether. Other ways of recruiting participants have been deployed successfully to achieve representative participation (at least up to a point), and if they were employed in concert with a CrowdLaw platform, the question still remains whether the model of participation enacted on the platform could be considered a democratic advance.

\subsection{What is the CrowdLaw model of participation?}

So should the model of participation on CrowdLaw platforms be considered a democratic advance? According to Cohen (1998), a democratic model of participation should give people bound by a collective decision an equal chance to influence that decision [39]. While any actual system is bound to fall short of this principle, we can ask whether the CrowdLaw model succeeds or could potentially succeed in creating a system that brings us closer to this ideal.

Let's begin by considering the GovLab's definition of CrowdLaw as simply crowdsourced lawmaking, without including a mechanism for online deliberation. A mechanism for online deliberation is not part of its definition. Should we feel satisfied that such a model could extend democratic participation? I would argue that no: if CrowdLaw was reduced to crowdsourcing participant feedback on policy, it would be tough to distinguish from polling, but with smaller and less representatives samples.

What makes the CrowdLaw model interesting is that, according to practitioners' understanding of it, it includes a mechanism for online discussion, perhaps even deliberation. Deliberation has been identified by a variety of theorists and researchers as a mechanism that can extend democratic participation: because it allows for more informed decision-making, encourages participants to revise their positions to move closer to the common good, provides them with the knowledge they need to better exercise their rights and duties as citizens, confers more legitimacy to decisions, and strives to reach a solution that is acceptable to all participants, not just to a majority $[16,17,30,32,39$, 40].

Researchers have similarly written about the benefits of online deliberation. While the Internet is far from being the magic tool for generating participation that CrowdLaw practitioners and the GovLab have made it out to be, it is still a powerful way of erasing spatial boundaries between people who want to be connected (at least on the digital side of the digital divide). Iyengar, Luskin and Fishkin (2003) argue that online deliberation can significantly cut the time and cost of face-to-face deliberation [41]. And they also find, along with other researchers, that online deliberation successfully approximates face-to-face deliberation $[17,42,43]$.

However, a look at the actual platform interfaces reveals that, while they do allow participants to have discussion, they do not reveal many design features that could encourage participants to have discussions that are closer to deliberation. More fundamentally, of all the projects that could credibly have an impact on the policy making process, Podemos and Open Ministry were the only one that showed no evidence of violating Cohen's (1998) principle of equal influence [39] - and that might have been because the Podemos and Open Ministry platforms could not be included in the analysis. All others showed evidence of a tiered participation model, either in the platform interfaces (Neos Lab and Icon Libya) or in the descriptions of the practitioners at the conference (Icon Libya, Marco Civil, Plataforma Brasil, Mudamos). There is also a more fundamental problem with some of the platforms that would probably be difficult to address through design changes: this is the problem of the tiered model of participation the author found on the platforms Neos Lab and Icon Libya, and also noted in the Brazilian projects.

That Neos Lab and Icon Libya restricted the opportunities for discussion and legal drafting to a minority of participants, and that the important discussion and decision-making happened off of the Brazilian platforms, is a sign that existing power holders may be less willing to cede control to citizens than they would like people to believe. At the same time, there is also evidence that it may be inherently difficult, even impossible to scale deliberation the same way as more conventional crowdsourcing inputs. Mansbridge (1983) notes that the larger the size of the group trying to reach a decision through deliberation, the less likely that the communicative conditions required for deliberation will be met [16]. In addition, the more diverse the 
deliberative group's interests are, the more likely an attempt at deliberation is to lead to coercion $[16,44]$. All this suggests that perhaps we should not expect platforms like the Neos Lab and Icon Libya to scale deliberation to their entire platform. Rather, if we want to create deliberative platforms that allow for equal participation, we might want to create smaller platforms, and deploy them in a more local context. Moreover, following most empirical research on deliberation, we might want to be wary of taking a one-size-fits-all approach to deploying deliberative CrowdLaw platforms that ignores the particularities of the local context [17].

\subsection{Is crowdsourced deliberation a promising model to extend democratic participation?}

So far, we've seen that there isn't much evidence that CrowdLaw as it's done in practice really constitutes a democratizing innovation. But if online deliberation can't be scaled, what does this tell us about the potential of crowdsourced deliberation in general to extend democratic participation?

There is one reason the CrowdLaw model shouldn't necessarily be discarded in favor of online deliberation: Aitamurto (2016), writing about what she calls "crowdsourced democratic deliberation," points out that one of its defining characteristics is that it is embedded in a larger process of policymaking, or at least gathering information for policymaking [45]. While not all the platforms I analyzed conformed to this criteria (Legislation Lab, as far as I can tell, is completely unmoored from any policymaking process), most platforms demonstrate a remarkably diverse integration into the larger policymaking process, demonstrating their versatility: Icon Libya, for example, was a UNbased effort, and fostered connections to universities, NGOs, and other forms of civil societies, according to its spokesperson Sean Deely. The negotiation of the Marco Civil involved a complex network of governmental and non-governmental stakeholders [23, 46], while the Neos Lab platform is directly connected to the legislative process through the nine seats its party holds in parliament [47].

This study only opens a small window into the world of e-participation interventions that are allegedly remaking the policy-making process. More research is needed in order to get an overview of the types of efforts that are occurring in this area. More in-depth research is also required in order to understand the effect of these interventions on the policy-making process, and the factors (like design choices, integration into the policy-making process) that moderate that effect. Hopefully what this study could show is that this is an area well worth looking into: both to keep the people honest who claim to use technology for democratic ends, and to apply the insights we can draw from academic work on democracy and the social capabilities of the Internet to contribute to the work of actually making our society more democratic.

\section{References}

[1] Dahlberg, L. (2001). The Internet and democratic discourse: Exploring the prospects of online deliberative forums extending the public sphere. Information, Communication \& Society, 4(4), 615-633.

[2] Friess, D. (2015). Online Deliberation Complete. Paper presented to the International Communication Association Conference, Puerto Rico, 21-25 May 2015

[3] Papacharissi, Z. (2002). The virtual sphere: The internet as a public sphere. New media \& society, 4(1), 9-27.

[4] Loader, B. D., \& Mercea, D. (2011). Networking democracy? Social media innovations and participatory politics. Information, Communication \& Society, 14(6), 757769.

[5] Kelty, C. M. (2017). Too much democracy in all the wrong places: toward a grammar of participation. Current Anthropology, 58(S15), S77-S90.

[6] Noveck, B. S. (2015). Smart citizens, smarter state: The technologies of expertise and the future of governing. Harvard University Press.

[7] United States Government. General Services Administration. (2009). Engaging Citizens in Government. Center for Intergovernmental Solutions.

[8] Goldsmith, S., \& Crawford, S. (2014). The responsive city: Engaging communities through data-smart governance. John Wiley \& Sons.

[9] Kitchin, R. (2014). The data revolution: Big data, open data, data infrastructures and their consequences. Sage.

[10] Benkler, Y. (2016). Degrees of freedom, dimensions of power. Daedalus, 145(1), 18-32.

[11] Boulos, M. N. K., Resch, B., Crowley, D. N., Breslin, J. G., Sohn, G., Burtner, R., ... \& Chuang, K. Y. S. (2011). Crowdsourcing, citizen sensing and sensor web technologies for public and environmental health surveillance and crisis management: trends, OGC standards and application examples. International journal of health geographics, 10(1), 67.

[12] Niemeyer, C., Wagenknecht, T., Teubner, T., \& Weinhardt, C. (2016, January). Participatory Crowdfunding: An approach towards engaging employees and citizens in institutional budgeting decisions. In System Sciences (HICSS), 2016 49th Hawaii International Conference on (pp. 28002808). IEEE.

[13] Wagenknecht, T., Levina, O., \& Weinhardt, C. (2017). Crowdsourcing in a Public Organization: Transformation and Culture.

[14] Governance Lab website 1. Retrieved from http://www.thegovlab.org/project-CrowdLaw.html

[15] Governance Lab website 2. Retrieved from http://www.thegovlab.org/about.html

[16] Mansbridge, J. J. (1983). Beyond adversary democracy. University of Chicago Press. 
[18] Aitamurto, T., Landemore, H., \& Saldivar Galli, J. (2016). Unmasking the crowd: participants' motivation factors, expectations, and profile in a crowdsourced law reform. Information, Communication \& Society, 1-22.

[19] Aitamurto, T., \& Landemore, H. (2016). Crowdsourced Deliberation: The Case of the Law on Off-Road Traffic in Finland. Policy \& Internet, 8(2), 174-196.

[20] Gluck, J., \& Ballou, B. (2014). New Technologies in Constitution Making. USIP, Washington.

[21] Gluck, J., \& Brandt, M. (2015). Participatory and Inclusive Constitution Making. United States Institute.

[22] Landemore, H. (2015). Inclusive Constitution-Making:

The Icelandic Experiment. Journal of Political

Philosophy, 23(2), 166-191.

[23] Hermosilla, M., \& Root, J. (2015, Oct.1). A growing community of \#CrowdLaw practitioners. Retrieved from http://thegovlab.org/a-growing-community-of-global-

CrowdLaw-practitioners/

[24] Castells, M. (2015). Networks of outrage and hope: Social movements in the Internet age. John Wiley \& Sons.

[25] Bonavida, I. (2012). Die "Neos" Liberalen. (2012, Oct. 18). Die Presse. Retrieved from

http://diepresse.com/home/innenpolitik/1303009/Die-

NeosLiberalen

[26] Finnish Population Register Center. Retrieved from http://vrk.fi/en/finnish-citizens-initiative

[27] Marco Civil hailed as step forward by righst activists. (2015, May 20). Financial Times. Retrieved from https://www.ft.com/content/222ce16e-cc95-11e4-b5a5-

00144 feab7de

[28] Lemos, R., Steibel, F., de Souza, C.A., Nolasco, J. (2014). A Bill of Rights for the Brazilian Internet ("Marco Civil") - A Multistakeholder Policy-Making Case. Retrieved from https://publixphere.net/i/noc/page/IG Case Study A Bill of Rights for the Brazilian Internet.

[29] Deely, S., \& Nash, T. N. (2014, January). The Future of Democratic Participation: my. con: An Online Constitution Making Platform. In Sintelnet WG5 Workshop on Crowd Intelligence: Foundations, Methods and Practices (p. 1).

[30] Abramson, J. B., Arterton, F. C., \& Orren, G. R. (1988).

The electronic commonwealth. The Impact of New Media Technologies on Democratic Politics, New York.

[31] Chambers, S. 2003. "Deliberative Democratic Theory." Annual Review of Political Science 6 (1): 307-26.

[32] Habermas, J. (1975). Legitimation Crisis. Boston: Beacon Press.

[33] Legislation Lab website. Retrieved from http://legislationlab.org/en/

[34] Mudamos website. Retrieved from https://itsrio.org/pt/projetos/mudamos-plataformas-para-umademocracia-participativa/

[35] Neos Lab website. Retrieved from https://ab.neos.eu/

[36] Marco Civil website. Retrieved from http://culturadigital.br/marcocivil/

[37] Goel, S., Anderson, A., Hofman, J., \& Watts, D. J. (2015). The structural virality of online diffusion. Management Science, 62(1), 180-196.

[38] Goel, S., Watts, D. J., \& Goldstein, D. G. (2012, June). The structure of online diffusion networks. In Proceedings of the 13th ACM conference on electronic commerce (pp. 623638). ACM.
[39] Cohen, J. (1998). Democracy and liberty. In J. Elster (Ed.), Deliberative Democracy (pp. 185-231). Cambridge University Press.

[40] Fearon, J. (1998). Deliberation as Discussion. In J. Elster (Ed.), Deliberative Democracy (pp. 44-68). Cambridge University Press.

[41] Iyengar, S., Luskin, R. C., \& Fishkin, J. S. (2003, August). Facilitating informed public opinion: evidence from face-to-face and online deliberative polls. In Annual Meeting of the American Political Science Association, Philadelphia.

[42] Price, V. (2009). Citizens deliberating online: Theory and some evidence. Online deliberation: Design, research, and practice, 37-58.

[43] Price, V., \& Cappella, J. N. (2002). Online deliberation and its influence: The electronic dialogue project in campaign 2000. IT \& Society, 1(1), 303-329.

[44] Jones, D. J., Turner, J., \& Montbach, J. (1992). Declining social services and the threat to social reproduction: an urban dilemma. City \& Society, 6(2), 99-114.

[45] Aitamurto, T. (2016). Crowdsourced democratic deliberation in open policymaking: Definition, promises, challenges. Browser Download This Paper.

[46] Apesar de aprovação, idealizador do Marco Civil da web prevê novas disputas. (2014, April 24). BBC Brasil. Retrieved from

http://www.bbc.com/portuguese/videos e fotos/2014/04/1404 24 nemundial lemos $\mathrm{mm} \mathrm{dg}$.

[47] Österreich - Nationalratswahl 2013. (2013). Bundesministerium für Inneres. Retrieved from http://wahl13.bmi.gv.at/. 